\title{
Adsorption of the Malachite Green by Magnetic Clam Shell Powder
}

\author{
Xiaodong Li ${ }^{1 *}$, Biao Wen ${ }^{2}$, Yunjin $\mathrm{Li}^{2}$ \\ 'Key Laboratory of Songliao Aquatic Environment, Ministry of Education, Jilin Jianzhu University, \\ Changchun 130118, China \\ ${ }^{2}$ School of Materials Science and Engineering, Jilin Jianzhu University, Changchun 130118, China
}

Received: 17 April 2020

Accepted: 9 June 2020

\begin{abstract}
Magnetic clam shell powder (MCS) was prepared from river clam shell by crushing, calcining at $900^{\circ} \mathrm{C}$ and $\mathrm{Fe}_{3} \mathrm{O}_{4}$ was loaded on it by chemical coprecipitation. The functional groups of the composites were characterized using Fourier transform infrared spectroscopy (FT-IR). Batch adsorption was conducted to study the effects of various parameters such as initial concentration, temperature, adsorbent dosage and other factors on adsorption. Through the study of adsorption isotherm model (Langmuir isotherm model, Freundlich isotherm model, Temkin isotherm model, Halsey isotherm model), kinetic model (quasi first order kinetics, quasi second order kinetics, Elovich model) and adsorption mechanism (intraparticle diffusion and Boyd models), it showed that the quasi-secondorder kinetic equation and Langmuir equation could describe the adsorption process well, and the intra particle diffusion, liquid film diffusion and chemical adsorption were important factors to control the reaction rate.
\end{abstract}

Keywords: magnetic river clam shell, malachite green, adsorption kinetics, adsorption isothermal model, adsorption mechanism

\section{Introduction}

Malachite green (MG) is a cationic dye of triphenylmethane, which has a strong inhibitory effect on protozoa and fungal infection. It is widely used as fungicide, insecticide [1], coloring agent in aquaculture and dye industry. However, scientific evidence indicates that $\mathrm{MG}$ is genetically toxic and carcinogenic. It affects aquatic organisms to a certain degree and has certain stimulation after the ingestion of human

*e-mail: 1xdjlju@163.com gastrointestinal tract [2]. $\mathrm{MG}$ is removed from the water system by adsorption, photocatalytic degradation and ultrasonic irradiation. Among these methods, adsorption technology is widely used to remove pollutants, especially dyes. Magnetic adsorption method has the characteristics of excellent magnetic properties, it is easy to be separated by external magnetic field and is reusable. Magnetic adsorbent has been proved to be effective in separating suspended adsorbents [3].

River clam shell is a composite material composed of $\mathrm{CaCO}_{3}$, a small amount of combined water and trace amount of organic matter. Its spatial structure is constituted of cuticle, prism and pearl layer. There are a lot of micropores between 2 and 10 microns in the 
prism layer, which have strong adsorption ability and can be used as dye adsorbent. After calcination, the carbon dioxide in the river clam shell of the layered structure turns into a gas and the material decomposition occurs. The initial pore channel changes and a new porous structure forms [4], thus its exchange and adsorption capacity are improved. River clam shell contains plenty of calcium carbonate, the content of which is up to $90 \%$. The calcined clam shell is alkaline, which is conducive to the adsorption of cationic dyes in water and accelerates the adsorption rate of dyes.

In order to reduce the environmental risks arising from the MG pollution in waste water, it is necessary to develop low-cost remedial adsorption technique using various natural wastes. In this study, the prepared magnetic river clam shell was used as an adsorbent to remove dye MG from aqueous solution. The investigation for dye removal was carried out through a series of batch adsorption experiments. The attention has been placed in an understanding of the kinetics, mechanisms and equilibrium processes involved in adsorption of MG onto the magnetic clam shell.

\section{Material and Methods}

\section{Materials}

In this study, river clam shell was taken from the lake in Changchun National Forest Park, washed and dried in a drying oven at $105^{\circ} \mathrm{C}$ for 6 hours. Malachite green $(\mathrm{MG}), \mathrm{FeCl}_{2} \cdot 4 \mathrm{H}_{2} \mathrm{O}, \mathrm{FeCl}_{3} \cdot 6 \mathrm{H}_{2} \mathrm{O}$ were purchased from aladdin, and all chemicals and reagents were of analytical grade. Deionized water was used for preparation of malachite green solutions with different concentrations.

Preparation of river clam shell powder: The dried river clam shell was pulverized, passed through a 200-mesh sieve, and placed in a desiccator for use. The obtained adsorbent was recorded as RCS.

Calcined river clam shell powder: The dried river clam shell was broken into small pieces, calcined at $900^{\circ} \mathrm{C}$, ground into a powder, passed through a 200-mesh sieve, and placed in a desiccator for use.

\section{Preparation of the Magnetic Clam Shell}

$100 \mathrm{~mL}$ deionized water in the beaker was heated in a constant temperature water bath. $2.7 \mathrm{~g}$ $\mathrm{FeCl}_{2} \cdot 4 \mathrm{H}_{2} \mathrm{O}$ and $4 \mathrm{~g} \mathrm{FeCl} \cdot 6 \mathrm{H}_{2} \mathrm{O}$ dissolve in water to form a stable dispersion system [5]. 4.7g shell powder was added to the solution and mixed well. $\mathrm{NH}_{3} \cdot \mathrm{H}_{2} \mathrm{O}$ is then dripped into the beaker in order to adjust the $\mathrm{pH}=8$. Simultaneously, a brown precipitate was formed. The mixture was heated for 2 hours in a water bath, allowed to stand for 15 minutes, washed several times with distilled water and $95 \% \mathrm{CH}_{3} \mathrm{CH}_{2} \mathrm{OH}$, filtered, dried, and ground for use. The prepared adsorbent was recorded as MCS.

\section{Batch Adsorption Experiments}

The surface functional groups of absorbent were characterized by FT-IR Spectrum100 Fourier infrared spectrometer. Thermogravimetric analysis (TGA) was performed by heating from room temperature to $1100^{\circ} \mathrm{C}$ with a constant heating rate of $10^{\circ} \mathrm{C} / \mathrm{min}$. The adsorption capacity and adsorption rate of adsorbent to MG were calculated by the following formula:

$$
\begin{gathered}
q_{t}=\frac{\left(C_{0-} C_{t}\right) \times \mathrm{V}}{m} \\
\eta=\frac{\left(C_{0-} C_{t}\right)}{C_{0}} \times 100 \%
\end{gathered}
$$

In the formula, $\mathrm{C}_{0}$ and $\mathrm{C}_{\mathrm{t}}$ are the concentration of the initial time and the time $\mathrm{t}$ of the $\mathrm{MG}$, respectively. $\mathrm{V}$ is the solution volume, and $\mathrm{m}$ is the mass of absorbent. The $0.03 \mathrm{~g}$ adsorbent is added to $500 \mathrm{ml} \mathrm{MG}$ of a certain concentration in a beaker. At room temperature, the solution was stirred by high-speed magnetic force, stood still, centrifuged, and the supernatant was taken measure MG concentration.

\section{Results and Discussion}

Fig. 1 is the Fourier transform infrared spectrum of prepared materials. From Fig. 1a), The C-O stretching vibration peak appeared at $1796 \mathrm{~cm}^{-1}$, the $\mathrm{C}-\mathrm{O}$ anti-symmetric stretching vibration appeared at $1517 \mathrm{~cm}^{-1}$, the $\mathrm{CO}_{3}^{2-}$ out-of-plane deformation vibration peak appeared at $867 \mathrm{~cm}^{-1}$, and the in-plane deformation vibration peak of $\mathrm{C}-\mathrm{O}$ appeared at $713 \mathrm{~cm}^{-1}$. The obvious vibration peak at $1796 \mathrm{~cm}^{-1}$ is attributed to the $\mathrm{C}=\mathrm{O}$ vibration peak of calcite-type carbonate, and there is a strong absorption peak at $1517 \mathrm{~cm}^{-1}$, which is the $\mathrm{v}_{3}$ characteristic absorption peak of calcite-type calcium carbonate crystal, representing the asymmetry

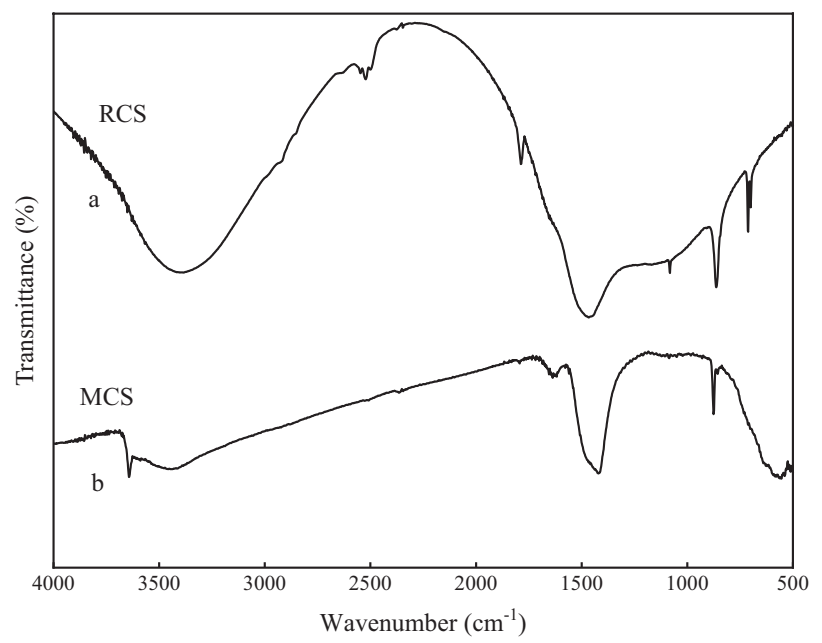

Fig. 1. FTIR spectra of RCS and MCS. 
of $\mathrm{C}-\mathrm{O}$ bond [6]. Absorption peaks of $867 \mathrm{~cm}^{-1}$ and $713 \mathrm{~cm}^{-1}$ are respectively $\mathrm{v}_{2}$ [7] and $\mathrm{v}_{4}$ absorption peaks in calcite crystal, $\mathrm{v}_{2}$ peak is strong and sharp, $\mathrm{v}_{4}$ peak is sharp but not as strong as $\mathrm{v}_{2}$, there is $\mathrm{C} \equiv \mathrm{N}$ peak at $2180 \mathrm{~cm}^{-1}$. In Fig. 1b), the characteristic peak of $\mathrm{CO}_{3}{ }^{2-}$ was significantly weakened, indicating that $\mathrm{CaCO}_{3}$ had been decomposed, and the vibration peak of $\mathrm{Fe}-\mathrm{O}$ bond appeared at $611 \mathrm{~cm}^{-1}$, indicating that $\mathrm{Fe}_{3} \mathrm{O}_{4}$ had been loaded successfully. In both figures, there is a characteristic peak in the segment $3400-3440 \mathrm{~cm}^{-1}$, indicating the expansion vibration of hydroxyl group or amino group.

Fig. 2 shows the results of TGA for the prepared samples. The decomposition process is mainly divided into two parts. The TGA curve show significantly exothermic peak and weight loss phenomenon in the temperature range of $217^{\circ} \mathrm{C}-369^{\circ} \mathrm{C}$, which indicates the organic matter in the river clam shell decomposes and releases heat. When the temperature rises to $683^{\circ} \mathrm{C}-896^{\circ} \mathrm{C}$ [8], the phenomenon of rapid weight loss and heat absorption occurs within a short time, which indicates that $\mathrm{CaCO}_{3}$, the main component of river clam shell, is decomposed into $\mathrm{CaO}$ and $\mathrm{CO}_{2}$ at high temperature at this stage. The decomposition reaction is as follows:

$$
\mathrm{CaCO}_{3} \rightarrow \mathrm{CaO}+\mathrm{CO}_{2} \uparrow
$$

The decomposition of organic matter and the escape of a large amount of $\mathrm{CO}_{2}$ make the pore structure of the river clam shell increased, and most of them are micropores of 2-10 $\mu \mathrm{m}$, which have strong adsorption capacity.

It can be seen from Fig. 3 that the adsorption amount of the two adsorbents (MCS and RCS) gradually increases with the increase of the initial concentration of MG. When the concentration reached $400 \mathrm{mg} / \mathrm{L}$, the adsorption gradually became equilibrium, indicating that in the high concentration of MG solution, the binding site on the surface of the adsorbent is near saturation. As can be seen from the figure, the

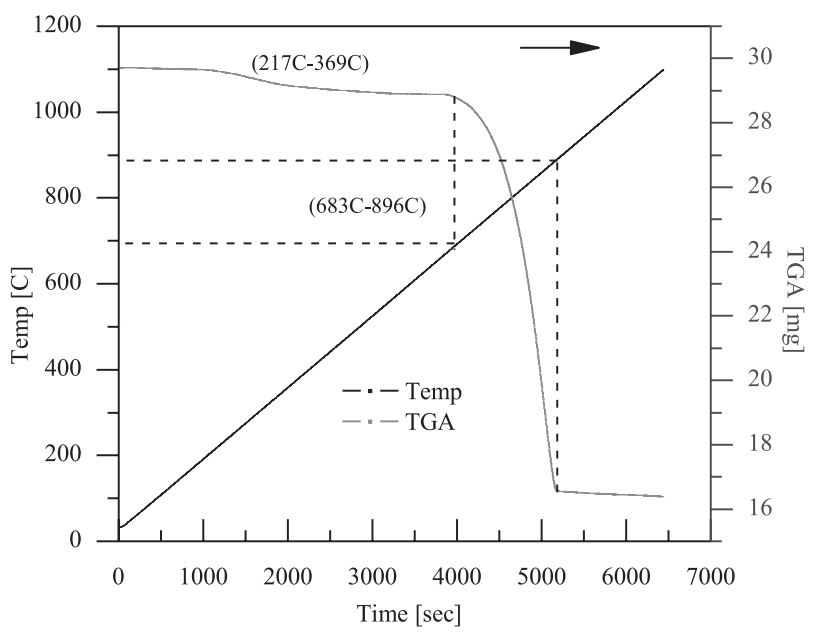

Fig. 2. TGA of river clam shell. equilibrium adsorption amount of MCS is about $25 \%$ higher than that of RCS. This is because the river clam shell is mainly composed of $\mathrm{CaCO}_{3}$ and a small amount of organic matter. The high temperature calcination causes decomposition of $\mathrm{CaCO}_{3}, \mathrm{CO}_{2}$ overflow and organic matter. The increase in calcination temperature resulted in the pore size of the river clam shell increase, while it can effectively improve the absorption of more malachite green molecules.

The concentration of the fixed malachite green solution was weighed $0.01,0.02,0.03,0.04,0.05 \mathrm{~g}$ of the adsorbent for static adsorption, and after $180 \mathrm{~min}$, the supernatant was centrifuged for measurement. The results are shown in Fig. 4. It can be seen that the adsorption rate of malachite green increases gradually with the increase in the adsorbent amount. At the same time, the adsorption amount decreases with the increase of the adsorbent. This phenomenon is consistent with the law of diminishing marginal effects of economics. As can be seen from the Fig. 4, when the MCS amount reached $0.03 \mathrm{~g}$, the adsorption rate increased rapidly and reached its maximum. When the MCS was $0.03 \mathrm{~g}-0.05 \mathrm{~g}$, the adsorption rate was basically stable without much improvement. Therefore, $0.03 \mathrm{~g}$ was selected as the optimal dosage in subsequent experiments.

a. Quasi-first order kinetic equation

$$
\ln \left(q_{e}-q_{t}\right)=\ln q_{e}-k_{1} t
$$

The adsorption capacity of equilibrium time adsorbent to $M G$ is described as $q_{e}(m g / g) \cdot q_{t}(m g / g): q_{t}$ is the amount of $\mathrm{MG}$ adsorbed by $\mathrm{t}$ time adsorbent. $\mathrm{k}_{1}$ is a quasi-first order rate constant.

b. Quasi second order kinetic equation

$$
\frac{d q_{t}}{d t}=k_{2}\left(q_{e}-q_{t}\right)^{2}
$$

For the limited conditions $t=0$ to $t=t$ and $q_{t}=0$ to $q_{t}=q_{t}$ the linear expression could be reduced to

$$
\frac{t}{q_{t}}=\frac{1}{k_{2} q_{2 e}^{2}}+\frac{t}{q_{2 e}}
$$

In Eq. (5), $\mathrm{q}_{\mathrm{e}}^{2}(\mathrm{mg} / \mathrm{g})$ is the adsorption amount of equilibrium time adsorbent to $\mathrm{MG}$. $\mathrm{qt}(\mathrm{mg} / \mathrm{g})$ is amount adsorb per gram of sorbent at any time $\mathrm{t}_{\mathrm{k}} \mathrm{k}_{2}$ was the rate constant of the quasi-second order kinetic equation [9]. c. Elovich model

$$
\frac{d q_{t}}{d t}=a_{1} \exp \left(-b_{1} q_{t}\right)
$$

When $\mathrm{t}=0, \mathrm{q}_{\mathrm{t}}=0$. Formula (6) was integrated, and the integral form is:

$$
q_{t}=\frac{1}{b_{1}} \ln \left(t+t_{0}\right)-\frac{1}{b_{1}} \ln \left(t_{0}\right)
$$




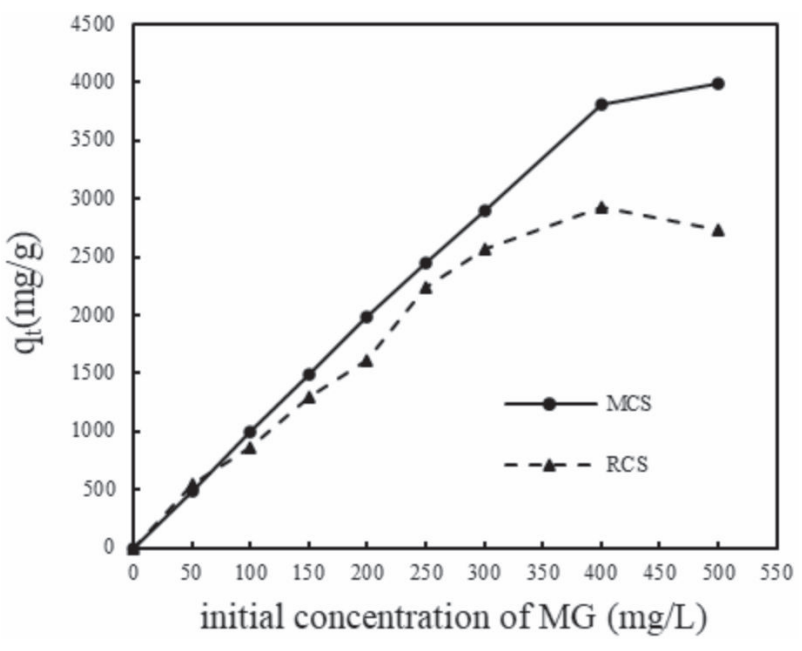

Fig. 3. Effect of initial concentration of MG on adsorption.

In Eq. (7), $t_{0}=\frac{1}{a_{1} b_{1}}$, If $\mathrm{t}$ was much larger than $\mathrm{t}_{0}$, formula (7) can be linearly reduced to:

$$
q_{t}=\frac{1}{b_{1}} \ln \left(a_{1} b_{1}\right)+\frac{1}{b_{1}} \ln (t)
$$

Eq. 8 could be reduced to

$$
q_{t}=A+B \ln (t)
$$

The quasi-first-order kinetic equation and quasisecond-order kinetic equation models assumed of physisorption and chemisorption process respectively [10]. The quasi-first-order kinetic equation can describe the adsorption controlled by the diffusion step. According to the fitting value of the linear expression of the quasi-first-order dynamic fitting equation, MCS $\left(\mathrm{R}^{2}=0.9258\right)$, the fitting value exceeds 0.9. MCS conforms to the first-order kinetic model, which indicates that the adsorption of MCS was completed by boundary diffusion.

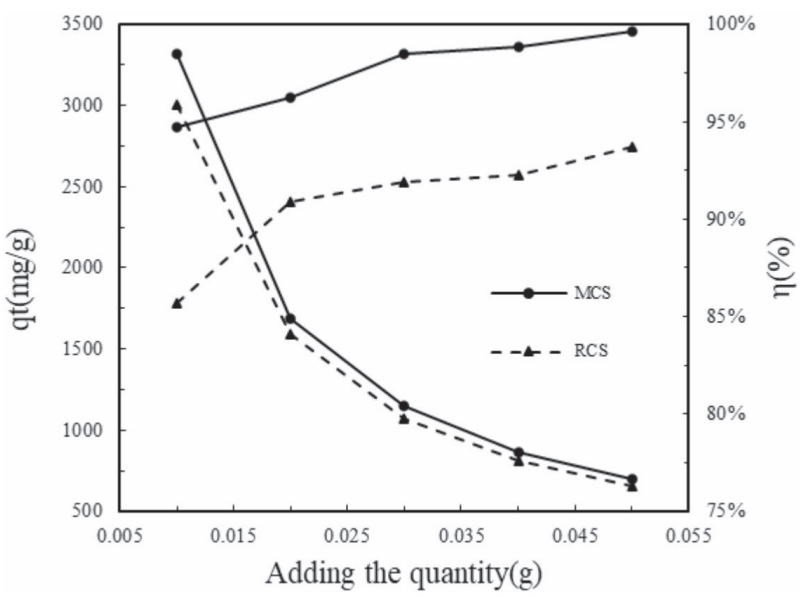

Fig. 4. Effect of dosage on adsorption.

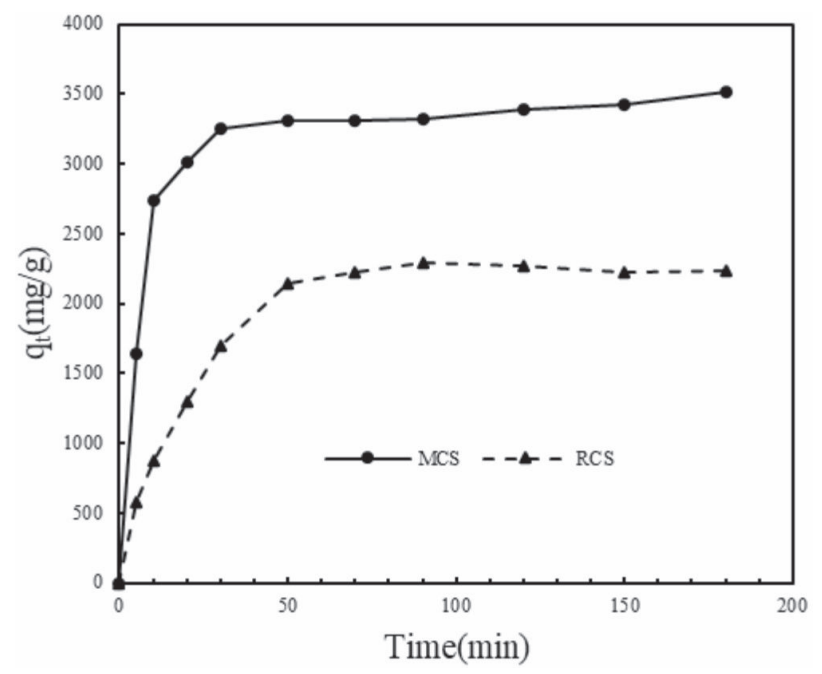

Fig. 5. The effect of adsorption time on adsorption quantity.

Eq. (5) was initially used successfully to describe electron sharing or transfer between the absorbents and adsorbates, and the whole adsorption process is described by the equation, which is affected by the rate of chemical adsorption. Meanwhile, the external liquid film diffusion, internal particle diffusion, intraparticle diffusion and surface adsorption, three adsorption processes are included in the whole adsorption process, which can completely describe the solid-liquid adsorption mechanism. The value of rate constants and statistical parameters for each kinetic model are shown in Table $1, \operatorname{MCS}\left(\mathrm{R}^{2}=0.9993\right)$, $\mathrm{RCS}\left(\mathrm{R}^{2}=0.9974\right)$. Quasi-second-order kinetic adsorption is initially affected by the formation of chemical bonds, which indicated that the adsorption process is chemisorption and that both of the two substances conformed to the whole complete adsorption process. The first step is the diffusion of the external liquid film, which has resistance to adsorption. MG particles transport through the hydrodynamic boundary layer of the adsorbent surface. The movement of particles outside the film is caused by molecular diffusion, so the transport rate of particles is affected by the thickness of the liquid layer. The thinner the boundary layer, the higher the rate of transportation. The second step is intra-particle diffusion. This process occurs when MG particles must be transported to the adsorption point through pores after passing through the liquid layer. The migration of particles in this process is completed by the diffusion of liquid in pores. In the third step, the MG particles are attached at an effective position of the adsorbent, such as pores or capillaries. The rate at which this step occurs is very fast, and this process can be thought of as instantaneous [11].

Eq. (8) was initially used successfully to describe the chemisorption of gas molecule onto the sorbent. The Elovich equation is used to describe the sorption system if it is chemisorption. It is also assumed that the adsorption active sites of the adsorbent are 


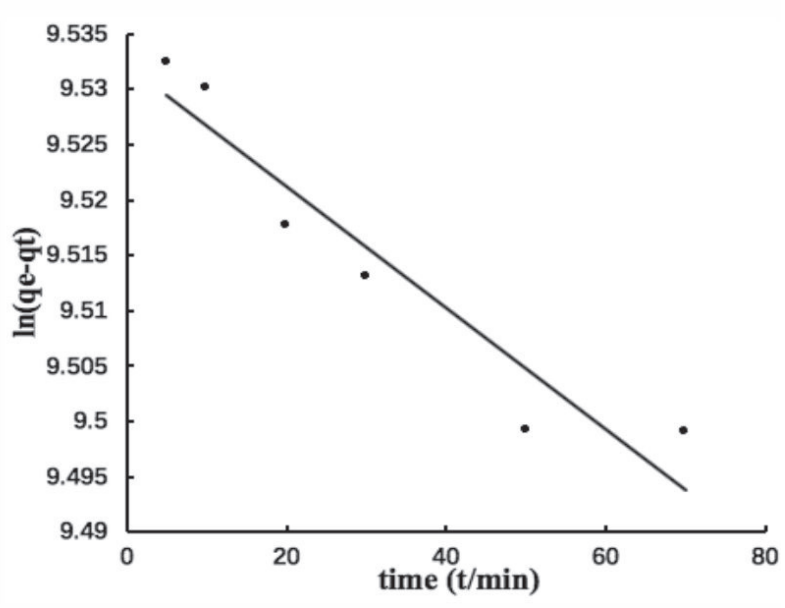

Fig. 6. MCS quasi first order dynamics.

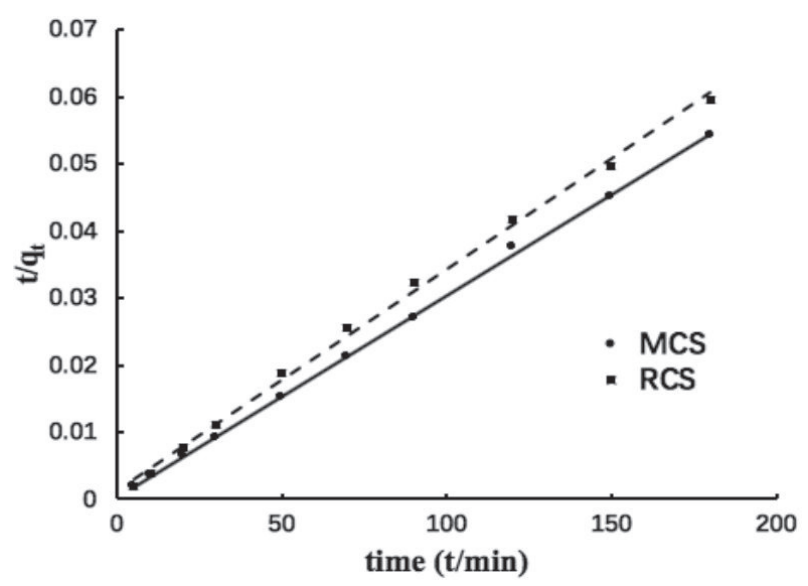

Fig. 8. Quasi second order dynamic model.

heterogeneous and exhibit different activation energies. According to the $\mathrm{R}^{2}$ of Elovich fitting equation, MCS (0.9501), RCS (0.7305), MCS can be described by this equation, indicating that the surface activation energy of the MCS surface is uniformly distributed during the adsorption process. By comparing the fitted values of the three models, we find that the quasi-second-order kinetic equation is best suited to describe the kinetic adsorption process of the two materials [12].

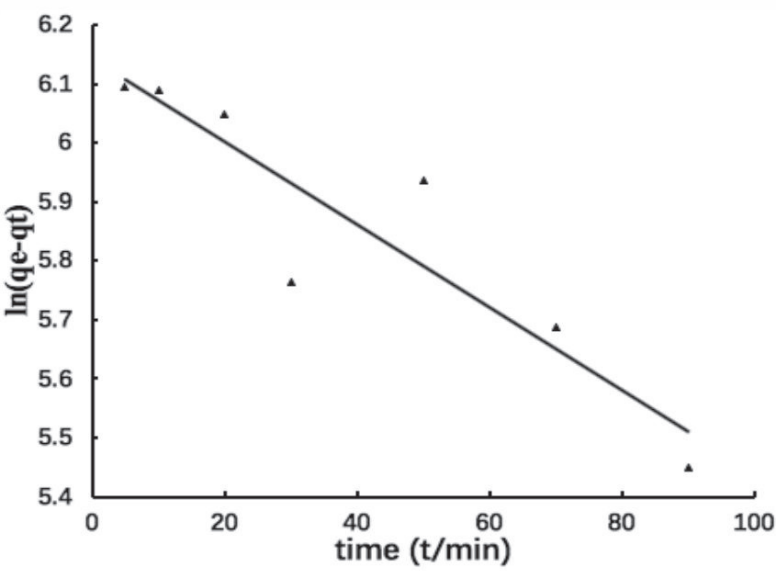

Fig. 7. RCS quasi first order dynamics.

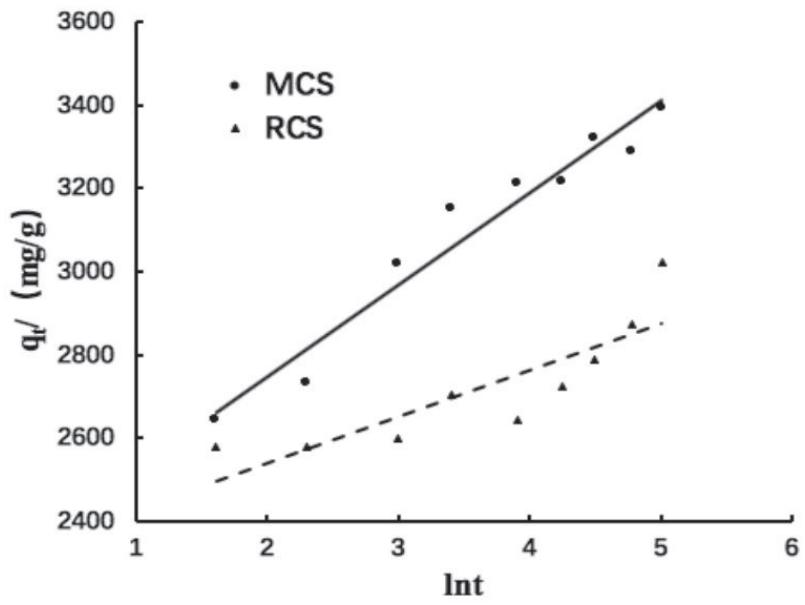

Fig. 9. Elovich model.

a. Langmuir isotherm model

$$
\frac{C_{e}}{q_{e}}=\frac{1}{q_{\max } K_{L}}+\frac{C_{e}}{q_{\max }}
$$

$\mathrm{C}_{\mathrm{e}}$ : $\mathrm{MG}$ molecule concentration in solution at equilibrium(mg/L). $\mathrm{q}_{\mathrm{e}}$ : Amount adsorb per gram of

Table 1. Adsorption kinetic parameter.

\begin{tabular}{|c|c|c|c|c|c|c|c|c|c|}
\hline & Quasi first & der dynan & c model & Quasi s & $\begin{array}{l}\text { cond order } d y \\
\text { model }\end{array}$ & Iamic & & Elovich mod & \\
\hline & $\begin{array}{c}\mathrm{q}_{1} \\
\mathrm{mg} / \mathrm{g}\end{array}$ & $\begin{array}{c}\mathrm{k}_{1} \\
/ \mathrm{min}\end{array}$ & $r_{1}^{2}$ & $\begin{array}{c}\mathrm{q}_{2} \\
\mathrm{mg} / \mathrm{g}\end{array}$ & $\begin{array}{c}\mathrm{k}_{2} \\
/ \mathrm{min}\end{array}$ & $r_{2}^{2}$ & $\begin{array}{c}\mathrm{A} \\
\mathrm{mg} / \mathrm{g}\end{array}$ & $\begin{array}{c}\text { B } \\
\mathrm{mg} / \mathrm{g} / \mathrm{min}\end{array}$ & $\mathrm{R}_{\mathrm{E}}^{2}$ \\
\hline 1CS & 852.863 & -0.0632 & 0.9258 & 3333.333 & $2.25 \times 10^{-4}$ & 0.9993 & 2308.5 & 219.65 & 0.950 \\
\hline ¿CS & 464.704 & -0.007 & 0.8398 & 3333.333 & $6.42 \times 10^{-5}$ & 0.9974 & 2320.8 & 110.51 & 0.730 \\
\hline
\end{tabular}


the sorbent at equilibrium $(\mathrm{mg} / \mathrm{g}) . \mathrm{q}_{\max }$ : Maximum adsorption capacity of single layer adsorbent (mg/g). $\mathrm{K}_{\mathrm{L}}$ : Langmuir constant $(\mathrm{L} / \mathrm{mg})$, it indicates the affinity of the adsorbent to the binding site of the adsorbate and the adsorption energy.

b. Freundlich isotherm mode

$$
\ln q_{e}=\ln K_{f}+\frac{1}{n} \ln C_{e}
$$

$\mathrm{K}_{\mathrm{f}}$ : Adsorbent relative adsorption capacity. n: Freundlich constants, intensity of sorption [13].

c. Temkin isotherm model

$$
q_{e}=b_{T} \ln K_{T}+b_{T} \ln C_{e}
$$

$\mathrm{b}_{\mathrm{T}}$ : Temkin constant. It relates to heat of adsorption $(\mathrm{J} /$ $\mathrm{mol}) . \mathrm{K}_{\mathrm{T}}$ : Temkin isotherm constant $(1 / \mathrm{g})$.

d. Halsey isotherm model

$$
\ln q_{e}=\left[\left(\frac{1}{n_{H}}\right) \ln K_{H}\right]-\left(\frac{1}{n_{H}}\right) \ln \left(\frac{1}{C_{e}}\right)
$$

$\mathrm{n}_{\mathrm{H}}$ : Halsey isotherm model constant. $\mathrm{K}_{\mathrm{H}}$ : Halsey isotherm model.

$$
R_{L}=\frac{1}{1+K_{L} C_{i}}
$$

The liquid phase molecules undergo an inelastic collision on the surface of the solid phase of the adsorbent as an adsorption process. The Langmuir isotherm equation is used to estimate the theoretical maximum equilibrium corresponding to the full coverage of the single layer surface at the same adsorption point. The feasibility of the Langmuir isotherm model can be expressed by the dimensionless constant separation factor $\left(\mathrm{R}_{\mathrm{L}}\right)$ [14].

$\mathrm{C}_{\mathrm{i}}$ is the initial concentration of $\mathrm{MG}$, whether the adsorbent is favorable for adsorption can be judged by $R_{L}$, and the value of $R_{L}$ has the following four cases: The adsorption process is irreversible adsorption when $\mathrm{R}_{\mathrm{L}}=0$. When $\mathrm{R}_{\mathrm{L}}=1$, it is linear adsorption, $\mathrm{R}_{\mathrm{L}}>1$ is not conducive to adsorption, and $0<\mathrm{R}_{\mathrm{L}}<1$ is favorable for adsorption. When the initial concentration is low, the $\mathrm{R}_{\mathrm{L}}$ of MCS is 0.057 , and the $R_{L}$ changes to $0.038\left(40^{\circ} \mathrm{C}\right)$ and $0.09\left(50^{\circ} \mathrm{C}\right)$ as the temperature increases. The $\mathrm{R}_{\mathrm{L}}$ of RCS is $0.601\left(30^{\circ} \mathrm{C}\right), 0.348\left(40^{\circ} \mathrm{C}\right), 0.101\left(50^{\circ} \mathrm{C}\right)$ respectively. All values of $R_{L}$ are less than 1 and greater than 0 . As the initial concentration increases to $500 \mathrm{mg} / \mathrm{g}$, the $\mathrm{R}_{\mathrm{L}}$ of two substances fall to 0.0059 (MCS) and 0.1307 (RCS) at $30^{\circ} \mathrm{C}$, respectively. When the temperature rises to $50^{\circ} \mathrm{C}, \mathrm{R}_{\mathrm{L}}=0.0099(\mathrm{MCS}), 0.0111$ (RCS). The values of $R_{L}$ gradually decrease and approach to 0 . It is indicated that all three substances are favorable for adsorption and gradually tend to be irreversible adsorption state as the concentration increases and the temperature increases. According to Table 1, we can find that the maximum adsorption capacity of MCS and RCS monolayers is $5000 \mathrm{mg} / \mathrm{g}$, which has a large adsorption amount. We speculate that the two materials have relatively complicated microporous structure and ideal mesoporous structure, but as the temperature increases, the maximum

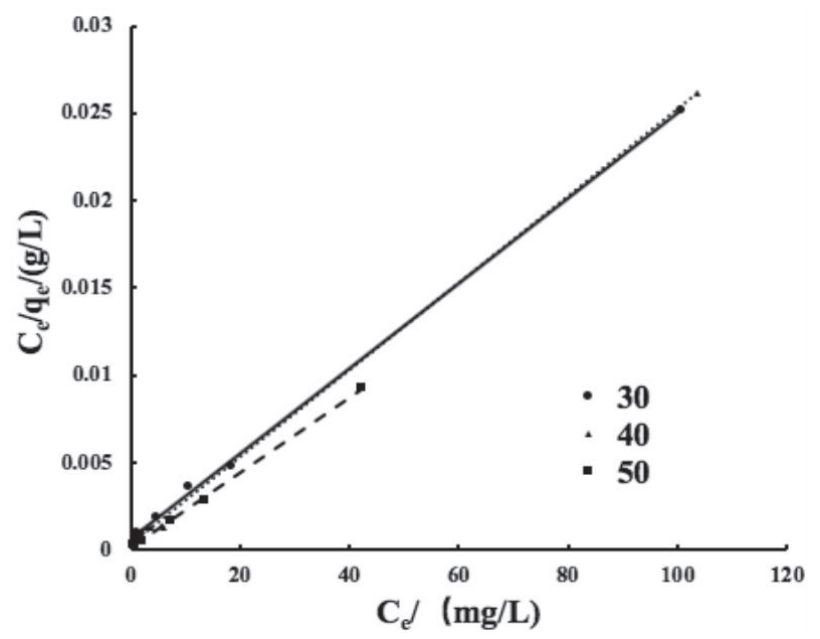

Fig. 10. MCS Langmuir isotherm model.

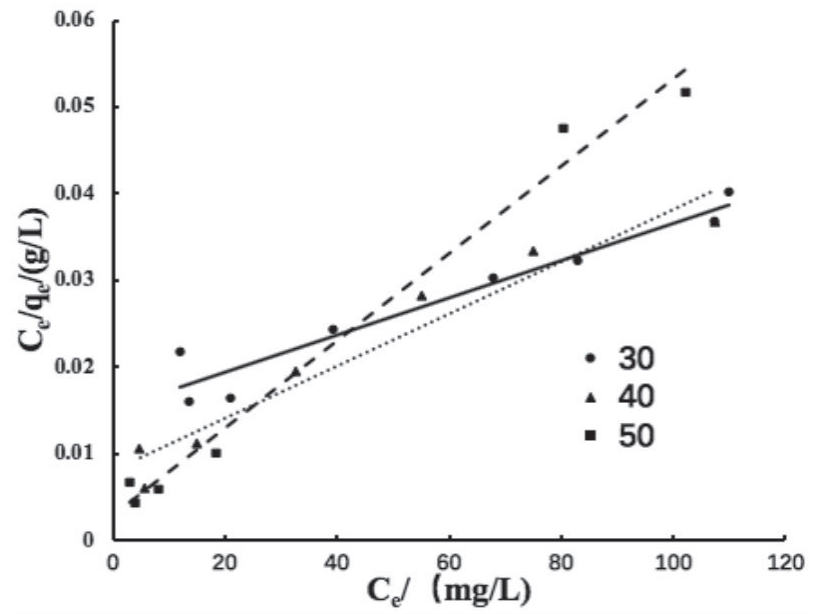

Fig. 11. RCS Langmuir isotherm model.

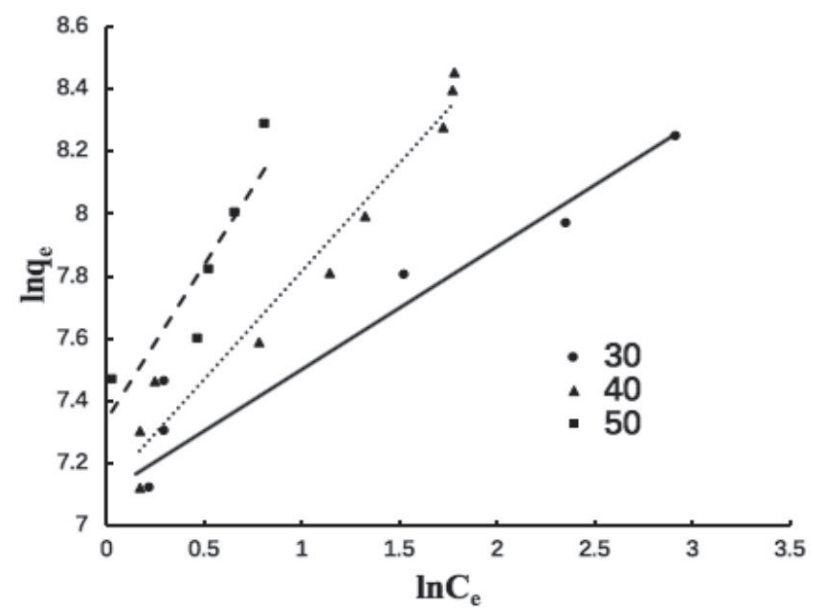

Fig. 12. MCS Freundlich isotherm model. 
adsorption capacity of RCS decreases, and the structure of RCS is destroyed with increasing temperature, which is more stable than MCS. At the same time, the

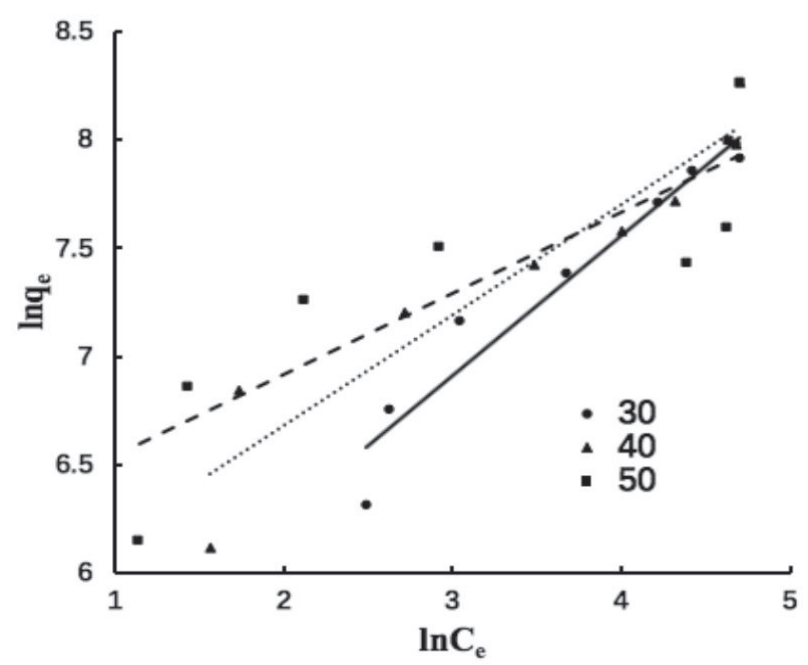

Fig. 13. RCS Freundlich isotherm model.

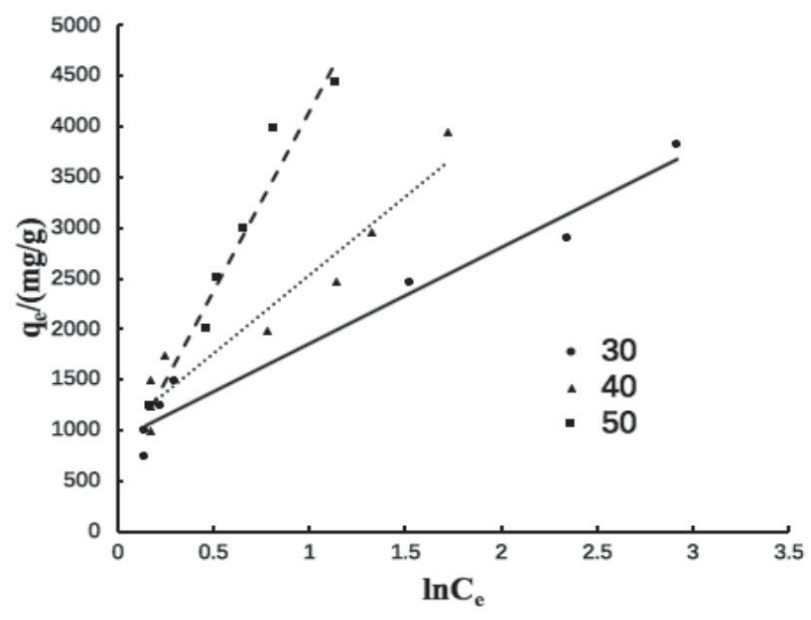

Fig. 14. MCS Temkin isotherm model.

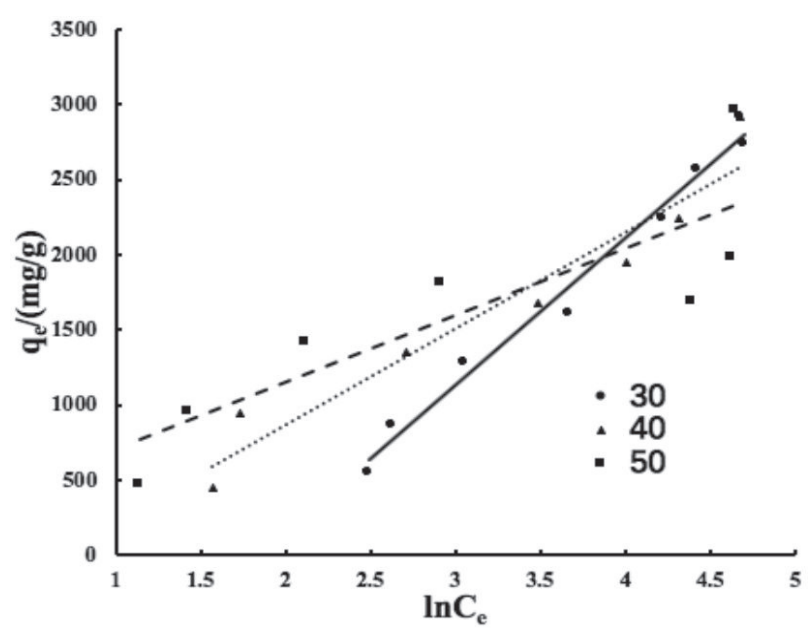

Langmuir equation results are consistent with the quasifirst-order dynamic equations [15].

The Freundlich isotherm is an empirical equation based on the adsorption occurring on the heterogeneous surface of the adsorbent. The Freundlich isotherm constants $\mathrm{n}$ and $\mathrm{K}_{\mathrm{f}}$ were empirical parameters that vary with the degree of heterogeneity and related to adsorption capacity. The adsorption capacity of the adsorbent is positively correlated with the $\mathrm{K}_{\mathrm{f}}$ of the Freundlich model. At the same time, the adsorption capacity of the adsorbent is positively correlated with the $\mathrm{K}_{\mathrm{f}}$ of the Freundlich model. It can be seen from Table 2 that the $\mathrm{K}_{\mathrm{f}}$ of the MCS is much larger than the RCS, so the adsorption capacity of the MCS is stronger than that of the RCS. The correlation constant $n$ of the Freundlich model is between 1 and 10, which is beneficial to the adsorption process. It can be seen from Table 2 that the $n$ values of MCS and RCS are all within $10.1 / \mathrm{n}$ reflects the magnitude of the adsorption strength [16], when $0.1<1 / \mathrm{n}<1$, it is advantageous for adsorption, and when $1 / \mathrm{n}>1$, adsorption cannot be performed. It can be calculated from Table 2 that the $1 / \mathrm{n}$ of MSC and RCS are 0.395 and 0.645 , and the MCS is lower than $\mathrm{RCS}$, indicating that MCS is more favorable for the adsorption of MG.

Halsey isotherm model was used to explain the multilayer adsorption system for $\mathrm{MG}$ molecule. The fitted value of MCS is equal to 0.9378 and the RCS is equal to 0.946 . It shows that both are in line with the multi-layer adsorption system.

According to the value of $\mathrm{R}^{2}$ at room temperature according to the theoretical model of Table 1-4, the theoretical balance of each isothermal model with different initial concentrations is compared with the experimental data, Langmuir $>$ Temkin $>$ Halsey $>$ Freundlich (MCS), and we can find Langmuir, The Temkin and Halsey model fit values above 0.9 can be used to describe MCS. In contrast, the Langmuir model is more suitable for describing the adsorption process of this material. Temkin $>$ Freundlich $=$ Halsey $>$ Langmuir, using the Temkin model to describe the adsorption process of MG by RCS.

a. Pore diffusion, intra-particle diffusion model

$$
q_{t}=k_{i} t^{0.5}+C
$$

$\mathrm{q}_{\mathrm{t}}$ : amount adsorb per gram of sorbent at any time $\mathrm{t}$ $(\mathrm{mg} / \mathrm{g}) . \mathrm{k}_{\mathrm{i}}$ : intra-particle rate constant $\left(\mathrm{mg} / \mathrm{g} / \mathrm{min}^{1 / 2}\right)$. $\mathrm{C}$ : intraparticle diffusion constant, will increase with the reduction of surface heterogeneity and hydrophilic groups of biochar.

b. Byod model [17]

$$
\begin{gathered}
B_{t}=-0.4977-\ln (1-F) \\
F=\frac{q_{t}}{q_{e}}
\end{gathered}
$$

Fig. 15. RCS Temkin isotherm model. 
Table 2. Langmuir isotherm model.

\begin{tabular}{cccccc}
\hline$q_{\max } /(\mathrm{mg} / \mathrm{g})$ & $\mathrm{K}_{\mathrm{L}} /(\mathrm{L} / \mathrm{mg})$ & $\mathrm{r}^{2}$ & $\mathrm{RCS}$ & $q_{\max } /(\mathrm{mg} / \mathrm{g})$ & $\mathrm{K}_{\mathrm{L}} /(\mathrm{L} / \mathrm{mg})$ \\
\hline 5000 & 0.333 & 0.9992 & $30^{\circ} \mathrm{C}$ & 5000 & 0.0133 \\
5000 & 0.5 & 0.9989 & $40^{\circ} \mathrm{C}$ & 3333.333 & 0.0375 \\
5000 & 0.2 & 0.9998 & $50^{\circ} \mathrm{C}$ & 2000 & 0.1786 \\
\hline
\end{tabular}

Table 3. Freundlich isotherm model.

\begin{tabular}{cccccc}
\hline $\begin{array}{c}K_{f}\left(\mathrm{mg}^{1-(1 / \mathrm{n})}\right. \\
1^{1 / \mathrm{n} / \mathrm{g})}\end{array}$ & $n(\mathrm{mg} / \mathrm{g}) /(\mathrm{mg} / \mathrm{L})^{1 / \mathrm{n}}$ & $\mathrm{r}^{2}$ & $\mathrm{RCS}$ & $\begin{array}{c}K_{f}\left(\mathrm{mg}^{1-(1 / \mathrm{n})}\right. \\
1^{1 / \mathrm{n} / \mathrm{g})}\end{array}$ & $\begin{array}{c}\mathrm{n} \\
(\mathrm{mg} / \mathrm{g}) /(\mathrm{mg} / \mathrm{L})^{1 / \mathrm{n}}\end{array}$ \\
\hline 1218.0421 & 2.5297 & 0.8913 & $30^{\circ} \mathrm{C}$ & 145.0966 & 1.5494 \\
1239.1736 & 1.4445 & 0.9596 & $40^{\circ} \mathrm{C}$ & 286.8330 & 1.9627 \\
1535.3290 & 9.9681 & 0.8288 & $50^{\circ} \mathrm{C}$ & 477.9949 & 2.6745 \\
\hline
\end{tabular}

Table 4. Temkin isotherm model.

\begin{tabular}{cccccc}
\hline $\mathrm{b}_{\mathrm{T}}$ & $\mathrm{K}_{\mathrm{T}}$ & $\mathrm{r}^{2}$ & $\mathrm{RCS}$ & $\mathrm{b}_{\mathrm{T}}$ & $\mathrm{K}_{\mathrm{T}}$ \\
\hline 947.82 & 2.6239 & 0.9628 & $30^{\circ} \mathrm{C}$ & 980.000 & 0.1581 \\
1535.6 & 1.9167 & 0.9286 & $40^{\circ} \mathrm{C}$ & 644.780 & 0.5177 \\
3548.5 & 1.1908 & 0.9501 & $50^{\circ} \mathrm{C}$ & 446.840 & 1.7773 \\
\hline
\end{tabular}

Table 5. Halsey isotherm model.

\begin{tabular}{cccccc}
\hline $\mathrm{n}_{\mathrm{H}}$ & $\mathrm{K}_{\mathrm{H}}$ & $\mathrm{r}^{2}$ & $\mathrm{RCS}$ & $\mathrm{n}_{\mathrm{H}}$ & $\mathrm{K}_{\mathrm{H}}$ \\
\hline 2.8393 & $7.6459 \times 10^{8}$ & 0.9378 & $30^{\circ} \mathrm{C}$ & 1.5494 & 2235.268 \\
1.3055 & 9291.1222 & 0.9352 & $40^{\circ} \mathrm{C}$ & 1.9627 & 66620.75 \\
1.0450 & 2365.7180 & 0.9825 & $50^{\circ} \mathrm{C}$ & 2.6745 & $1.4661 \times 10^{7}$ \\
\hline
\end{tabular}

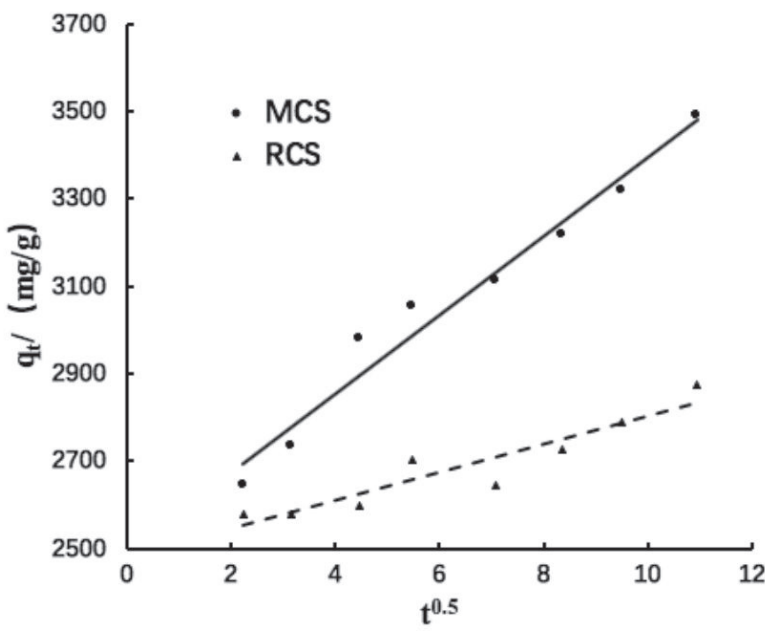

Fig. 16. Pore diffusion, intra-particle diffusion model.

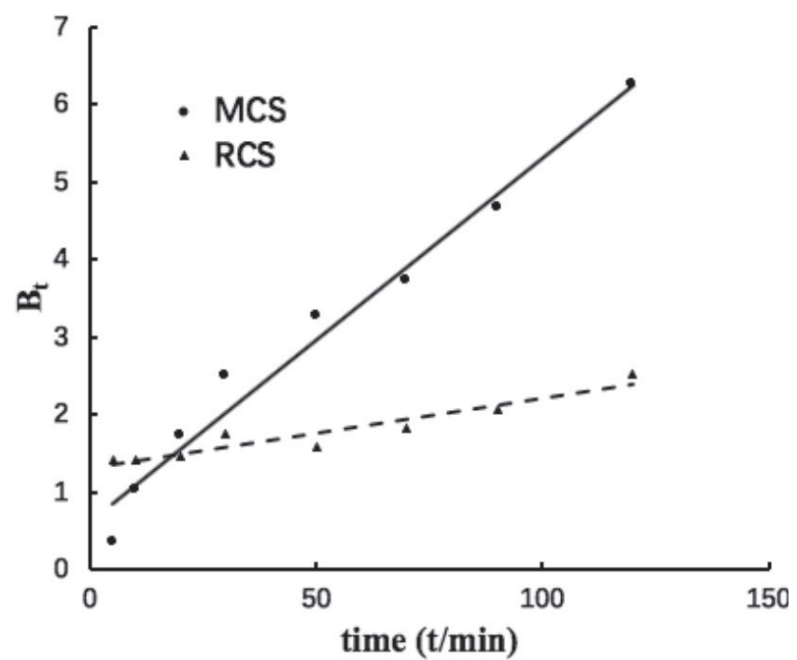

Fig. 17. Byod model. 
In the above equation: $\mathrm{F}$ represents the adsorption conversion rate at time $\mathrm{t} ; \mathrm{B}_{\mathrm{t}}$ is the mathematical function of F.

In the intra-particle diffusion model, we plot a linear curve for $t^{0.5}$ according to Eq. (15) $\mathrm{q}_{\mathrm{t}}$ as shown in Fig.17. If the fitted straight line passes through the origin, the intraparticle diffusion is the only rate control step. The linear equation of the two fitted straight lines is $y=90.34 x+2489.3$ (MCS). We can find that the straight line does not pass through the origin, indicating that MCS has other speed-control steps in addition to intraparticle diffusion in the process of adsorbing $\mathrm{MG}$ [18].

The Boyd model can be used to identify the rate limiting factor of the adsorption process. Using $B_{t}$ to plot $t$, if it is a straight line passing through the origin, it indicates that the intraparticle diffusion is the main control rate of the whole adsorption process. If the origin is not passed, it indicates that the liquid film diffusion or chemical reaction controls the adsorption rate. It can be seen from Fig.18 that the fitted straight line does not pass the origin. The results indicate that during the adsorption process of MG. Intraparticle diffusion, liquid membrane diffusion and chemisorption simultaneously control the rate of this process.

\section{Conclusions}

The adsorption reaction is affected by the initial concentration of dye, adsorption time, dosage, temperature, etc., combined with adsorption effect and economic benefit, etc., $0.03 \mathrm{~g}$ sample is taken at room temperature for $350 \mathrm{~min} / \mathrm{L}$ dye adsorption for $180 \mathrm{~min}$, and the experimental adsorption rate is more than $90 \%$. The quasi-first-order kinetic equation, the quasi-secondorder kinetic equation and the Elovich equation are used to analyze the kinetics of the adsorption process. The quasi-second-order kinetic equation is suitable for describing the adsorption process, indicating that the adsorption process is chemisorption. The process was analyzed by several isothermal models of Langmuir, Freundlich, Temkin and Halsey. The Langmuir model is more suitable for describing the adsorption process of MCS. The Temkin model is more suitable for describing RCS. Using the intraparticle diffusion model and the Byod model to explore the adsorption mechanism, it is concluded that intraparticle diffusion, liquid membrane diffusion and chemical adsorption jointly control the rate of the whole process.

\section{Acknowledgements}

This study was supported by Science Research Project of Education Department, Jilin Province from the 13th Five-Year Plan (JJKH20200265KJ) and the National Natural Science Foundation of China (No 61705077).

\section{Conflict of Interest}

The authors declare no conflict of interest.

\section{References}

1. DUBREIL E., MOMPELAT S., KROMER V., GUITTON Y., DANION M., MORIN T., HURTAUDPESSEL D., VERDON E. Dye residues in aquaculture products: Targeted and metabolomics mass spectrometric approaches to track their abuse. Food Chemistry, 294, 355, 2019.

2. JIANG F., DINH D.M., HSIEH Y.L. Adsorption and desorption of cationic malachite green dye on cellulose nanofibril aerogels. Carbohydrate Polymers, 173, 286, 2017.

3. KEFENI K.K., MAMBA B.B., MSAGATI T.M. Application of spinel ferrite nanoparticles in water and wastewater treatment: A review. Separation and Purification Technology, 188, 399, 2017.

4. YE K. Research on adsorption and passivation of cadmium and lead in wastewater and soil by calcined oyster shell powder. Hangzhou Dianzi University, China, pp. 126-134, 2018.

5. LU Z., LIU M.S., GE N.J., ZHANG Y.Z., REN Y., LI N., Zhang Y.Q. Optimization and characterization of $\mathrm{Fe}_{3} \mathrm{O}_{4} @$ (DS-LDH) synthesis conditions. Chemical Research and Application, 32 (02), 194, 2020.

6. SADER M.S., KANTHI L., SOARES G.A., LEGEROS R.Z. Simultaneous incorporation of magnesium and carbonate in apatite: effect on physico-chemical properties. Materials Research, 16 (4), 779, 2013.

7. ASIKIN-MIJAN N., TAUFIQ-YAP Y.H., LEE H.V. Synthesis of clamshell derived $\mathrm{Ca}(\mathrm{OH})$, nano-particles via simple surfactant -hydration treatment. Chemical Engineering Journal, 262, 1043, 2015.

8. NURDIN S., MISEBAH F.A., YUNUS R.M., MAHMUD, M.S., SULAIMAN, A.Z. Conversion of Jatropha curcas Oil to Ester Biolubricant Using Solid Catalyst Derived from Saltwater Clam Shell Waste (SCSW). I. J. of Chemical, Nuclear, Metallurgical and Materials Engineering- ISIWASET, 8 (9), 939, 2014

9. YANG X., YI H.H., TANG X.L., ZHAO S.Z., YANG Z.Y., MA Y.Q., FENG T.C., CUI X.X. Behaviors and kinetics of toluene adsorption-desorption on activated carbons with varying pore structure. Journal of Environmental Sciences, 67, 104, 2018.

10. SINGHA B., DAS S.K. Adsorptive removal of $\mathrm{Cu}$ (II) from aqueous solution and industrial effluent using natural/agricultural wastes. Colloids and surfaces B: Biointerfaces, 107C, 97, 2013.

11. QUEK A., BALASUBRAMANIAN R. Removal of copper by oxygenated pyrolytic tire char: Kinetics and mechanistic insights. Journal of Colloid and Interface Science, 356 (1), 203, 2011.

12. SANGON S., HUNT A.J., ATTARD T.M., MENGCHANG P., NGERNYEN Y., SUPANCHAIYAMAT N. Valorisation of waste rice straw for the production of highly effective car- bon based adsorbents for dyes removal. Journal of Cleaner Production, 172 (12), 145, 2018.

13. VICENTE D.O.S.N., MELO D.Q., DE OLIVEIRA T.C., NONATO R., TEIXEIRA P., SILVA MARCOS ANTÔNIO ARAÚJO. Evaluation of new chemically modified coconut shell adsorbents with tannic acid for $\mathrm{Cu}$ (II) removal from 
wastewater. Journal of Applied Polymer Science, 131 (18), 2014.

14. WANG H.J, LAN Y.B., LI X.D. Hydrothermal synthesis of $\mathrm{KMnO}_{4}$ modified rice husk and rice straw and its adsorption properties. Applied Chemical Industry, 48 (6), 1344, 2019

15. OLSEN S.R., WATANABE F.S. A method to determine a phosphorus adsorption maximum of soils as measured by the Langmuir isotherm. Soil Science Society of America Journal, 21, 144, 1957.

16. NAUTIYAL P., SUBRAMANIAN K.A., DASTIDAR M.G. Adsorptive removal of dye using biochar derived from residual algae after insitu transesterification: Alternate use of waste of biodiesel industry. Journal of Environmental Management, 182, 187, 2016.

17. FOO K.Y., HAMEED B.H. Utilization of oil palm biodiesel solid residue as renewable sources for preparation of granular activated carbon by microwave induced $\mathrm{KOH}$ activation. Bioresource Technology, 130, 696, 2013.

18. SOUZA P.R., DOTTO G.L., SALAU NINA PAULA GONÇALVES. Analysis of intraparticle diffusion on adsorption of crystal violet on bentonite. Chemical Engineering Communications, 206 (11), 1474, 2019. 